\title{
CANCER CERVIX SCREENING AT RURAL CAMP
}

\author{
N. Hephzibah Kiruamani ${ }^{1}$
}

1Professor, Department of Obstetrics and Gynaecology, Saveetha Medical College, Thandalam, Chennai, Tamilnadu, India.

ABSTRACT
BACKGROUND
Cancer cervix is preventable, yet it is the leading cause of morbidity and mortality among gynaec cancer. Various screening tests
are available, but due to lack of awareness among many women they are not utilizing it. We wanted to determine the distribution
of various cervical lesions in the selected rural population and determine effectiveness of visual inspection with Acetic acid-VIA
screening test and to compare VIA with Pap smear

\section{METHODS}

This is a cross sectional observational study conducted at Mannur village of Thiruvallur District. 312 women between 30-65 years were included in the study. Screening test for cancer cervix was conducted in three rural camps. Written informed consent was obtained from all. After detailed history and clinical examination women underwent concurrent screening tests namely Pap smear and VIA. Women with abnormal VIA and Pap smear were counselled and offered further management.

\begin{abstract}
RESULTS
Mean age of screened women was 42.4 years. Women over 60 years refused screening. $82 \%$ of women did not have symptoms related to cancer cervix. Mean age at first coitus was 21.6 years. $96 \%$ were parous women. Speculum examination revealed that cervix was normal in 41\%, abnormal in $49.4 \%$, and $9.6 \%$ had friable growth on the cervix. VIA was positive in $61 \%$ and in Pap smear 58\% were Normal and 42\% were abnormal. Biopsies were taken from VIA positive cases and from abnormal Pap smear. Biopsy report in $60.33 \%$ was normal, in $26.44 \%$ report was LSIL, and in $11.57 \%$ report was HSIL and in situ in $1.45 \%$. Cryosurgery was performed in 19 women and 8 women underwent TAH at Govt. Hospital. We were able to follow up and complete the treatment only for 27 (56.25\%) women out of 48 women with abnormal biopsy report. VIA had a sensitivity of $75.41 \%$ and specificity of $90.6 \%$, positive predictive value $68.94 \%$, and negative predictive value of $95.37 \%$. Pap smear had a sensitivity of $85.23 \%$, specificity of $95.12 \%$, positive predictive value of $66.77 \%$, negative predictive value of $92.85 \%$.
\end{abstract}

\section{CONCLUSIONS}

To reduce the burden of cancer cervix, VIA is a simple screening test which can be done easily in rural camp. When VIA combined with Pap smear, precancerous lesion detection rate will be increased. We were able to follow up and complete the treatment only for 27 (56.25\%) women out of 48 women with abnormal biopsy report.

\section{KEY WORDS}

Cancer Cervix, Screening, Pap Smear, Cryosurgery, Visual Inspection with Acetic Acid

HOW TO CITE THIS ARTICLE: Kiruamani NH. Cancer cervix screening at rural camp. J. Evolution Med. Dent. Sci. 2019;8(28): 2247-2250, DOI: $10.14260 /$ jemds/2019/492

\section{BACKGROUND}

Though cancer cervix is on the decreasing trend, still it continues to be a major health problem.(1) In recent years there is evidence that life style changes had occurred due to increase in economic standards and education status. Life span has increased, and aging population is increasing. These two factors are responsible for increase burden of cancer.(2) Among gynaec cancers, cervix cancer is the leading cause for morbidity and mortality. In urban settings though there is declining trend in cervical cancer but contributes leading cancer in India. It may be due to better awareness for genital hygiene.

'Financial or Other Competing Interest': None.

Submission 29-03-2019, Peer Review 30-06-2019,

Acceptance 05-07-2019, Published 15-07-2019.

Corresponding Author:

N. Haphzibah Kiruamani,

\#58/2,

Paripoorna Vinaagar Oil Street,

Mylapore, Chennai-600004,

Tamilnadu, India.

E-mail: hepsi002@yahoo.co.in

DOI: $10.14260 /$ jemds/2019/492
Cancer cervix shows decline trend may be due to change in trend in age of the marriage family planning procedures, improvement in education and socio-economic status. In the year 1992- 93 marriage age at 18 years was $54.2 \%$ but it was reduced to $44.5 \%$ in the year 2005- 06. Similarly, parity distribution was reduced from $3.39 \%$ in $1992-93$ to $2.68 \%$ in 2005- 06, hence there is change in risk factors for cancer cervix ${ }^{(3)}$ Cancer cervix is a preventable condition and various screening methods like visual inspection with acetic acid, VIA or with iodine VILI, Papanicolaou cytology, and colposcopy are available, but mortality due to cancer cervix is not reduced in India. VIA is a low cost and feasible screening method. Various integrated Nationwide and Tamil Nadu State programme for prevention and control of cancer are available. Women with risk factors do not undergo for screening test due to lack of awareness. They do not undergo opportunistic screening too. Another reason for not undergoing screening test is due to lack of accessibility in rural area. In pap smear there are some problems like cost and availability of cytologist to report hence simpler techniques like VIA and VILI were developed. This test can be done in low resource setting, can be done by paramedical personal and can be done in rural camp. 


\section{Aims and Objectives}

- To determine the distribution of the cervical lesions in the selected rural population.

- To determine the effectiveness of VIA as screening test.

- To compare VIA with Pap smear test.

\section{METHODS}

This was a cross- sectional observational study conducted at Mannur village of Thiruvallur district after obtaining IEC clearance and after informed consent. Three free camps were conducted at the interval of one month at community welfare centers. Each time 100 women from 30 years to 65 years belonging, to low socioeconomic group were screened Total of 312 women based on the prevalence of that area were screened after taking detailed history like white discharge PV, post coital bleeding, menstrual history, obstetric history, contraceptive history, family history and clinical evaluation, speculum examination and pelvic examination was done. Pap smear and VIA were done concurrently. Conventional Pap smear was done. Scarping was taken from squamocolumnar junction with Ayer's spatula and material taken is spread on the slides and fixed with Cytofix and it was transferred to cytologist. This is followed by VIA. On cervix $5 \%$ acetic acid was applied with cotton swab and cervix was examined after 1-2 minutes in adequate light with hand lens. Both tests were done by gynaecologist who conducted the camps free of cost. Findings of VIA was noted. Pap smear was sent to cytologist. VIA and Pap smear sensitivity and specificity were compared. Women with abnormal findings in VIA and in Pap smear were referred to nearby Govt. hospital and were followed up with Colposcopic directed biopsy and appropriate management was done. Based on the report they were offered either cryosurgery or hysterectomy. Statistical mean calculation was done for age distribution. For VIA and Pap smear Sensitivity, Specificity, Positive predictive value and Negative predictive value was calculated

\section{RESULTS}

\begin{tabular}{|c|c|c|}
\hline Parity & Number & Percentage \\
\hline Nulliparous & 12 & $4 \%$ \\
\hline $1-2$ & 115 & $37 \%$ \\
\hline $3-4$ & 131 & $42 \%$ \\
\hline$>4$ & 54 & $17 \%$ \\
\hline \multicolumn{2}{|c|}{ Table 1. Parity Distribution } \\
\hline \multicolumn{2}{|c|}{$\begin{array}{l}\text { Four percent were nulliparous, 37 \% belongs to para-1 -2, fourty two percentage. } \\
\text { Para 3-4 and 17\% were Para 4 and above. }\end{array}$}
\end{tabular}

\begin{tabular}{|c|c|c|}
\hline Speculum Examination Findings & Number & Percentage \\
\hline Cx appeared Normal & 128 & $41 \%$ \\
\hline Mild Erosion & 118 & $38 \%$ \\
\hline Badly Eroded & 66 & $21 \%$ \\
\hline Frank Growth & 3 & Not included for analysis \\
\hline \multicolumn{2}{|c|}{ Table 2. Speculum Examination Findings } \\
\hline \multicolumn{2}{|c|}{}
\end{tabular}

Cervix was appearing Normal in $41 \%$, mild erosion in $38 \%$ badly eroded cervix in $21 \%$, rank growth in 3 cases and these three cases not included in the study.

\begin{tabular}{|c|c|c|}
\hline VIA & No & Percentage \\
\hline Positive & 190 & $61 \%$ \\
\hline Negative & 122 & $39 \%$ \\
\hline \multicolumn{2}{|c|}{ Table 3. Visual Inspection with Acetic Acid Report } \\
\hline \multicolumn{2}{|c|}{ Sixty-one percentage women were VIA positive and 39\%were VIA negative. } \\
\hline
\end{tabular}

\begin{tabular}{|c|c|c|}
\hline Pap Smear Report & Number & Percentage \\
\hline Negative for Intraepithelial Lesion & 181 & $58 \%$ \\
\hline LSIL & 94 & $30 \%$ \\
\hline HSIL & 35 & $11.5 \%$ \\
\hline \multicolumn{2}{|c|}{ Table 4. Pap Smear Report } \\
\hline With features suspicious of invasion & 2 & $0.5 \%$ \\
\hline Normal and inflammatory Pap smear was seen in 58\%, LSIL was reported in 30\%, \\
HSIL was reported in 11.5\% and in situ was reported in 0.5\%. \\
\hline
\end{tabular}

\begin{tabular}{|c|c|c|c|}
\hline Biopsy Report & No. & Percentage & Treatment Offered \\
\hline Normal & 73 & $60.33 \%$ & Annual screening \\
\hline LSIL & 32 & $26.44 \%$ & 19 underwent Cryotherapy \\
\hline HSIL & 14 & $11.57 \%$ & 8-TAH \\
\hline In situ & 2 & $1.45 \%$ & Referred to cancer Institute \\
\hline Table 5. Cervix Biopsy Report and Follow Up of 121 Women \\
\hline
\end{tabular}

\begin{tabular}{|c|c|c|}
\hline & VIA & Pap Smear \\
\hline Sensitivity & 75.41 & 85.23 \\
\hline Specificity & 90.6 & $95.12 \%-$ \\
\hline Positive Predictive Value & $68.94 \%$ & $66.77 \%$ \\
\hline Negative Predictive Value & 95.37 & $92.85 \%$ \\
\hline \multicolumn{2}{|c|}{ Table 6. Specificity \& Sensitivity of VIA \& Pap Smear } \\
\hline
\end{tabular}

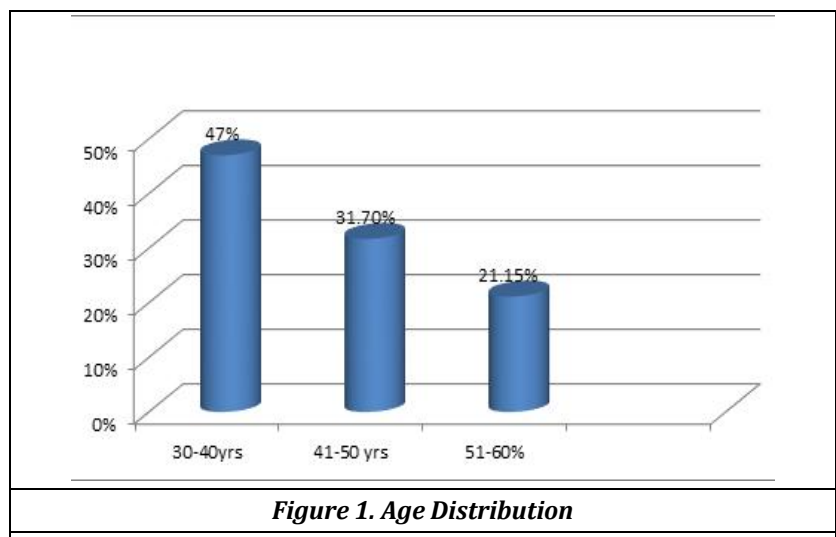

In the age group between $30-40$ years $47.1 \%$, in $41-50$ years $31.7 \%$ and in $51-60$ years $21.15 \%$ were screened. Mean age of women screened was 42.40 years.

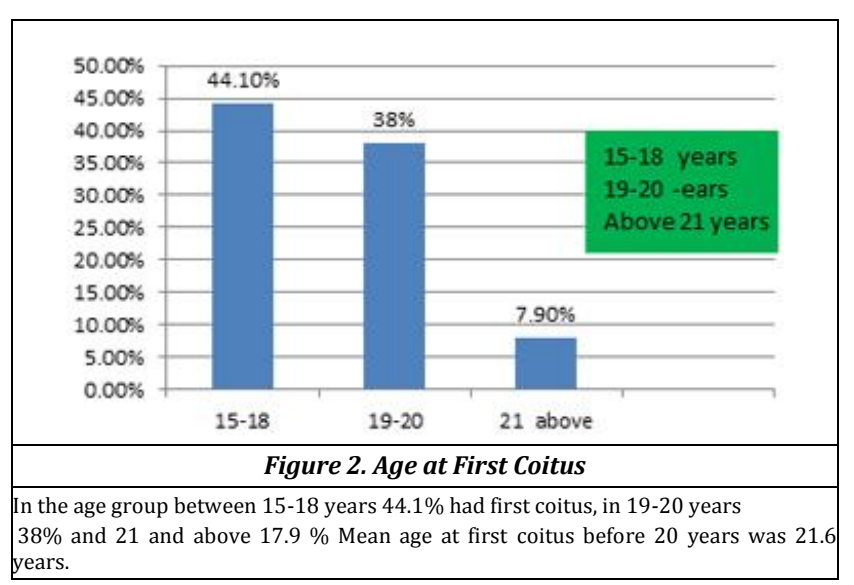

years.

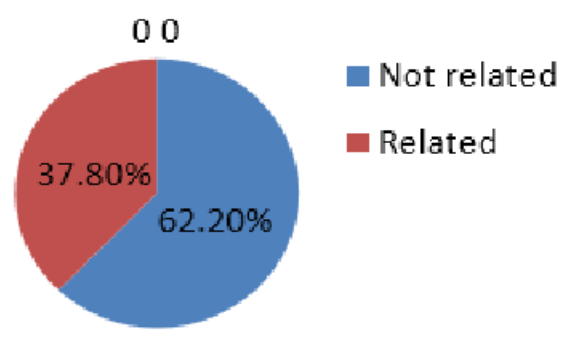

Figure 3. Complaints Among Women Screened

$62.20 \%$ of women did not have complaints related to cancer cervix, $37.8 \%$ of the women had complaints related to cancer cervix.

No significant reductions in the numbers of advanced cancers or deaths were observed in the cytologic-testing group or in the VIA group, hence studies are conducted to assess the effect of a single round of screening by testing for human papillomavirus (HPV) 4. Rate of cancer cervix among Muslims is less. This may be due to male circumcision which reduces the transmission of Human Papilloma Virus.(2) 
Primary prevention with vaccination to unmarried women and for married women Pap smear screening to be insisted as per guidelines. ${ }^{(4)}$

In this study $30-40$ years $47.1 \%$, in 41 - 50 years $31.7 \%$ and in 51- 60 years $21.15 \%$.were screened (Fig. 1) women after 60 years refused for screening. Mean age of women screened was 42.4 years. Standard deviation of +--19 . Mean age at first coitus was 21.6 years. $44.1 \%$ had first coitus before the age of 20 (Fig. 2) 96\% were parous women (Table 1) Sixty two percentage of women did not have complaints related to cancer cervix (Fig. 3) Speculum examination revealed Normal appearing cervix in $41 \%$, mild erosion in $38 \%$ badly eroded cervix in $21 \%$, frank growth in $9.6 \%$ and these three cases not included in the study (Table 2) Sixty one percent were VIA positive (Table 3) Normal and inflammatory Pap smear was seen in 58\%, LSIL was reported in $30 \%$, HSIL was reported in $11.5 \%$ and In situ was reported in $0.5 \%$ (Table 4) VIA positive women and Pap smear abnormal women were taken to nearby Govt. hospital for Colposcopy directed biopsy. Out of 190 women 69 women (36.31\%) were not willing for further follow-up. Out of 121 women $60.33 \%$ biopsy report were normal, in $26.44 \%$ report were LSIL, in $11.57 \%$ report were HSIL, In situ $1.45 \%$. (Table 5) Nineteen women with LSIL underwent Cryotherapy and 8 HSIL underwent-TAH, in situ cases were referred to cancer Institute. We were able to follow up and complete the treatment only for 27 (56.25\%) women out of 48 women with abnormal biopsy report. VIA had a sensitivity of $75.41 \%$ and specificity of $90.6 \%$ positive predictive value $68.94 \%$ and negative predictive value of $95.37 \%$ Pap smear had a sensitivity of $85.23 \%$, specificity of $95.12 \%$, positive predictive value of $66.77 \%$, negative predictive value of 92.85\%

All 190 VIA positive and abnormal Pap smear women were taken to nearby Govt. hospital for biopsy. Out of 190 women 69 women $(36.31 \%)$ were not willing and refused to come for further follow up. Out of 121 women $60.33 \%$ biopsy report were normal, in $26.44 \%$ report were LSIL, in $11.57 \%$ report were HSIL and in two cases report was in situ were Pap smear report showed features of suspicious of invasion and referred to cancer institute We were able to follow up and complete the treatment only for 27 (56.25\%) women out of 48 women with abnormal biopsy report. VIA had a sensitivity of $75.41 \%$ and specificity of $90.6 \%$ positive predictive value $68.94 \%$. and negative predictive value of $95.37 \%$. Pap smear had a sensitivity of $85.23 \%$, specificity of $95.12 \%$, positive predictive value of $66.77 \%$, negative predictive value of $92.85 \%$.

\section{DISCUSSION}

Cancer cervix is a preventable condition yet $88 \%$ of cancer cervix occur in low resource area Bradford L et al. ${ }^{1}$ Cancer cervix is high among low socio-economic women because of poor hygiene, lack of awareness about symptomatology, screening programme and treatment. Hence this study was conducted to screen rural women for cancer cervix at three villages in Thiruvallur district. Thus, we made an attempt to reduce burden of the disease among rural women by screening them. In the present study age group screened was between 30-65 years which is similar to Usha Rani Poli ${ }^{5}$ et al study. In this study $37.8 \%$ women had cancer related complaints but in E. L. Low et $\mathrm{al}^{6}$ study $44 \%$ had symptoms related to malignancy. Speculum findings in this study was mild erosion in 38\% and badly eroded cervix $21 \%$ and frank growth in $9.6 \%$. In Hend S. Saleh ${ }^{7}$ study commonest speculum examination finding was $38 \%$ chronic cervicitis.

In the present study VIA was done by gynaecologist and comparison was done between Pap smear and VIA with histopathology. Hedge et al $^{8}$ study VIA positive is more than Pap smear VIA was positive in $27(12 \%)$ patients and the Pap smear was abnormal in 26 (11.7\%) Jeronimo J ${ }^{9}$ et al more women were tested positive by VIA than on the Pap smear (6.9\% vs. $4.2 \%$; $P=0.0001$. In Sankaranarayanan $\mathrm{R}^{10}$ et al study pooled sensitivity, specificity, positive and negative predictive values of VIA were $80 \%, 92 \%, 10 \%$ and $99 \%$, respectively and in this study sensitivity $75.41 \%$ and specificity of $90.6 \%$ positive predictive value $68.94 \%$ and negative predictive value of $95.37 \%$. In Sinha et al ${ }^{11}$ study Pap smear was found to be more specific than VIA, i.e., 72.9 versus $60 \%$. Partha Basu et $\mathrm{al}^{12}$ in his study concluded mass screening of population is based on their population participation and in this study $36.31 \%$ not participated in complete work up and were lost to follow up. We were able to follow up and complete the treatment only for 27 (56.25\%) women out of 48 women with abnormal biopsy report. In the present study Pap smear had a sensitivity of $85.23 \%$, specificity of $95.12 \%$, positive predictive value of $66.77 \%$, negative predictive value of $92.85 \%$. Ajenifuja KO et $a^{13}$ study concluded VIA is insensitive compared to Pap smear and in this study Pap smear is more sensitive compared to VIA. As both VIA and Pap smear were combined in our study and detection rate is increased as suggested by Sarian L et al. ${ }^{14}$ Study conducted by Saleh $\mathrm{H}$ et al ${ }^{15}$ concluded that screening the cancer cervix best option is to combine both VIA and Pap smear. Pap smear had a better sensitivity and specificity than VIA, VIA is comparable to Pap smear in sensitivity and specificity.

\section{CONCLUSIONS}

VIA can be done easily in camp. Pap smear requires additional cost and needs cytologist to report. When screening combined with VIA and Pap smear, sensitivity and specificity is high in detecting precancerous lesions of cervix. VIA test can be done in remote and in rural camp settings since it is simple, acceptable and accessible screening test. To increase the acceptance rate among rural women we have to empower the women and awareness should increase.

\section{REFERENCES}

[1] Bradford L, Goodman A. Cervical cancer screening and prevention in low-resource settings. Clin Obstet Gynecol 2013;56(1):76-87.

[2] Badwe RA, Dikshit R, Laversanne M, et al. Cancer incidence trends in India. Jpn J Clin Oncol 2014;44(5):401-7.

[3] Shastri SS, Mitra I, Mishra G, et al. Effect of visual inspection with acetic acid (VIA) screening by primary health workers: randomized controlled study in Mumbai, India. ASCO Annual Meeting 203, Plenary Abstract No.2. http:// meeting library.asco.org/content/112133-32. 
[4] Gajalashmi CK, Shantha V. A study on association between cervical and penile cancers in Madras, India. Acta Oncol 1993;32(6):617-20.

[5] Poli UR, Bidinger PD, Gowrishankar S. Visual Inspection with Acetic Acid (VIA) Screening Program: 7 years' experience in early detection of cervical cancer and pre-cancers in rural south India. Indian J Community Med 2015;40(3):203-7.

[6] Low EL, Simon AE, Waller J, et al. Experience of symptoms indicative of gynaecological cancers in UK women. British Journal of Cancer 2013;109(4):882-7.

[7] Saleh HS. Can visual inspection with acetic acid be used as an alternative to Pap smear in screening cervical cancer? Middle East Fertility Society Journal 2014;19:187-91.

[8] Hegde D, Shetty H, Shetty PK, et al. Diagnostic value of acetic acid comparing with conventional Pap smear in the detection of colposcopic biopsy-proved CIN. Journal Cancer Research and Therapuetics 2011;7(4):454-8.

[9] Jeronimo J, Morales O, Horna J, et al. Visual inspection with acetic acid for cervical cancer screening outside of low-resource settings. Rev Panam Salud Publica 2005;17(1):1-5.

[10] Sankaranarayanan R, Nessa A, Esmy PO, et al. Visual inspection methods for cervical cancer prevention. Best Practice Res Clinical Obstet Gynaecol 2012;26(2):221-32.
[11] Sinha P, Srivastava P, Srivastava A. Comparison of visual inspection with acetic acid and the pap smear for cervical cancer screening. Acta Cytological 2018;62(1):34-8.

[12] Basu P, Sarkar S, Mukherjee S, et al. Women's perceptions and social barriers determine compliance to cervical screening: results from a population based study in India. Cancer Detect Prev 2006;30(4):369-74.

[13] Ajenifuja KO, Gage JC, Adepiti AC, et al. A populationbased study of visual inspection with acetic acid (VIA) for cervical screening in rural Nigeria. International Journal of Gynecological Cancer 2013;23(3):507-12.

[14] Sarian L01, Derchain SF, Naud P, et al. Evaluation of visual inspection with acetic acid (VIA), Lugol's iodine (VILI), cervical cytology and HPV testing as cervical screening tools in Latin America. This report refers to partial results from the LAMS (Latin American Screening) study. Journal of Medical Screening 2005;12(3):142-9.

[15] Saleh HS, El Hameid AAA, Mowafy HE, et al. Visual Inspection of the Cervix with (Acetic Acid or Lugols Iodine) for cervical cancer screening. Journal of HPV and Cervical Cancer 2016;1:111. 